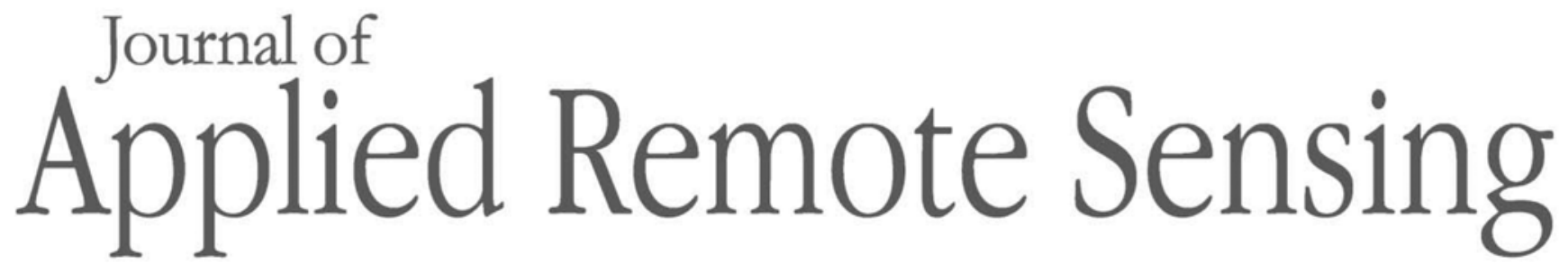

RemoteSensing.SPIEDigitalLibrary.org

\title{
Assessing land leveling needs and performance with unmanned aerial system
}

Juan Enciso

Jinha Jung

Anjin Chang

Jose Carlos Chavez

Junho Yeom

Juan Landivar

Gabriel Cavazos 


\title{
Assessing land leveling needs and performance with unmanned aerial system
}

\author{
Juan Enciso, ${ }^{\text {a,* Jinha Jung, }}$ Anjin Chang, ${ }^{\mathrm{b}}$ Jose Carlos Chavez, ${ }^{\mathrm{a}}$ \\ Junho Yeom, ${ }^{\mathrm{b}}$ Juan Landivar, ${ }^{\mathrm{a}}$ and Gabriel Cavazos ${ }^{\mathrm{c}}$ \\ ${ }^{a}$ Texas A\&M AgriLife Research and Extension Center, Weslaco, Texas, United States \\ ${ }^{\mathrm{b}}$ Texas A\&M University Corpus Christi, Corpus Christi, Texas, United States \\ ${ }^{c}$ United States Department of Agriculture, Natural Resource Conservation Service, Edinburg, \\ Texas, United States
}

\begin{abstract}
Land leveling is the initial step for increasing irrigation efficiencies in surface irrigation systems. The objective of this paper was to evaluate potential utilization of an unmanned aerial system (UAS) equipped with a digital camera to map ground elevations of a grower's field and compare them with field measurements. A secondary objective was to use UAS data to obtain a digital terrain model before and after land leveling. UAS data were used to generate orthomosaic images and three-dimensional (3-D) point cloud data by applying the structure for motion algorithm to the images. Ground control points (GCPs) were established around the study area, and they were surveyed using a survey grade dual-frequency GPS unit for accurate georeferencing of the geospatial data products. A digital surface model (DSM) was then generated from the 3-D point cloud data before and after laser leveling to determine the topography before and after the leveling. The UAS-derived DSM was compared with terrain elevation measurements acquired from land surveying equipment for validation. Although $0.3 \%$ error or root mean square error of $0.11 \mathrm{~m}$ was observed between UAS derived and ground measured ground elevation data, the results indicated that UAS could be an efficient method for determining terrain elevation with an acceptable accuracy when there are no plants on the ground, and it can be used to assess the performance of a land leveling project. () The Authors. Published by SPIE under a Creative Commons Attribution 3.0 Unported License. Distribution or reproduction of this work in whole or in part requires full attribution of the original publication, including its DOI. [DOI: 10 .1117/1.JRS.12.016001]
\end{abstract}

Keywords: unmanned aerial vehicles; land leveling; surface irrigation.

Paper 170618 received Jul. 13, 2017; accepted for publication Dec. 6, 2017; published online Jan. 2, 2018.

\section{Introduction}

The need for efficient water management has been intensified by a reduced supply of water due to drought and urban growth. UAS equipped with advanced remote sensors can serve as a good tool to help farmers make good agricultural management decisions and implement efficient water conservation practices. Due to advances in unmanned aerial vehicles (UAV) and remote sensor technologies, now it is possible to integrate various remote sensors into UAS platforms to acquire low altitude and ultrafine spatial resolution remote sensing data. ${ }^{1,2}$ Combined with the state-of-the-art big data processing and geospatial data analysis, the UAS can offer an innovative opportunity for the improvement of irrigation efficiencies by providing detailed information on the current field condition. ${ }^{3}$

Several remote sensors have been utilized in the past to determine the timing of irrigation using indexes such as water stress indices, crop water stress index (CWSI), and water deficit indexes. ${ }^{4-6}$ For example, scientists have added some variables such as canopy temperature to establish more general relations between vegetation indexes and crop evapotranspiration. Canopy temperature has been linked to crop evapotranspiration and soil moisture depletion

*Address all correspondence to: Juan Enciso, E-mail: Juan. Enciso@ag.tamu.edu 
of the soil, using the CWSI. ${ }^{5,7}$ Most of the remote sensing applications in irrigation engineering have been oriented toward detecting water stresses so that limited water resource can be more effectively utilized to maximize yields. However, the first main step for water conservation and improvement of irrigation efficiencies, especially in surface irrigated systems, is to level the land properly. Surface irrigation is the most commonly used system in the world. Surface irrigation can be a very efficient irrigation system if the fields and land are leveled and if the system is properly designed and managed. Leveling the land allows transporting and distributing water uniformly over the field as fast as possible with minimal field management. Land leveling provides the capability to utilize water labor and energy resources more efficiently. ${ }^{8}$ Land leveling consists of modifying the land topography, either to have zero slopes or to have a gradient in the soil to move water faster and efficiently over the field. Although land leveling is an efficient way of increasing efficiency of the water resource throughout the growing season, it is a rather expensive procedure, and, in some cases, a significant amount of earthwork may be required depending on the condition of the field. Advanced sensors must be used to determine parts with the higher terrain, and top soil from the higher terrain must be cut to deposit into the lower terrain. One of the most critical tasks in land leveling in agricultural fields is to minimize cuts and fills, and UAS can be used to measure the topography of the terrain continuously. A digital terrain model (DTM) generated from the UAS data can be used to evaluate if a major land leveling operation or a simple retouch of the land is needed. The main objective of this study is to assess the potential use of UAS to assess the elevations of a grower's field. UAS data were acquired before and after laser leveling of the land, and they are compared with ground measured terrain elevation to assess the accuracy of the UAS measured terrain elevation.

\section{Material and Methods}

This study was conducted in a farmer cooperator field with an area of 7 ha, located in Weslaco, Texas, at a latitude of $27^{\circ} 46^{\prime} 35^{\prime \prime} \mathrm{N}$ and a longitude of $97^{\circ} 33^{\prime} 38^{\prime \prime} \mathrm{W}$. The field is located in Villa Verde of Hidalgo County. The land was cleared of brush, crop residue, trash, and vegetative material that could have reduced the effectiveness of the leveling operation on July 7, 2016. The land was smoothed to firm the soil, so the terrain elevation survey can be performed accurately on the same day that UAS data were collected. A land survey and mapping of the field was conducted by setting a uniform grid system of 15.25 by $15.25 \mathrm{~m}$ on the field. The survey was done with a Trimble receiver (model R8 GPS receiver, Trimble, Dayton, Ohio), which was installed in the middle of the field. Then, a rod and data collector was moved through the points of the grid to obtain the coordinate and ground heights at each point. The coordinates of a total of 762 points were acquired using the Trimble receiver. The plan method was used to determine the new field slope. ${ }^{8}$ The plan method is a simple linear regression fit of field elevations of a twodimensional plane. The land surveying method was used to determine the cuts and fills required to provide the desired slope.

The field was leveled on July 23, 2016, following the conservation practice standard, ${ }^{9}$ with a land scraper (model 155TS2, Ashland, Wisconsin) and with a tractor (Massey Ferguson 8690, Duluth, Georgia). The land leveling process consisted of main cuts in the higher parts of the field and fills in the lowest parts.

Aerial images were acquired from a DJI Phantom 4 platform, which is manufactured by DJI (Shenzhen, China), on July 18, 2016, and September 19, 2016. These dates were chosen so that UAS data can be acquired before and after laser leveling the land. The RGB camera mounted on the phantom 4 takes 12 megapixels images. The data collected from these flights were processed using a structure from motion (SfM) algorithm to generate orthomosaic images (Fig. 1) and DTMs (Fig. 2) in the study area. A total number of 1233 raw images were obtained from the first flight with $85 \%$ forward and side overlap at $20 \mathrm{~m}$ altitude, and a total number of 904 raw images were collected from the second flight with $85 \%$ forward and side overlap at $20 \mathrm{~m}$ altitude. Approximate locations of raw images (longitude, latitude, and altitude) were recorded by an onboard GPS. However, its accuracy is not high enough for direct georeferencing. Six ground control points (GCPs) were installed around and in the middle of the study area for accurate georeferencing, geocorrection, and coregistration of UAS data. Four GCPs were 
(a)



Before (b)

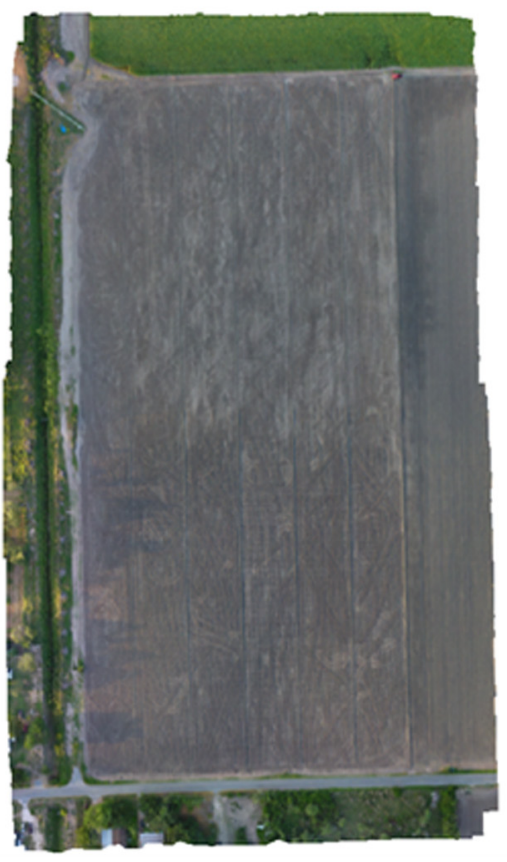

After

Fig. 1 Orthomosaic images from the study area of the leveled field generated from UAS data acquired on (a) July 18, 2017 and (b) September 19, 2017.

(a)



Before (b)

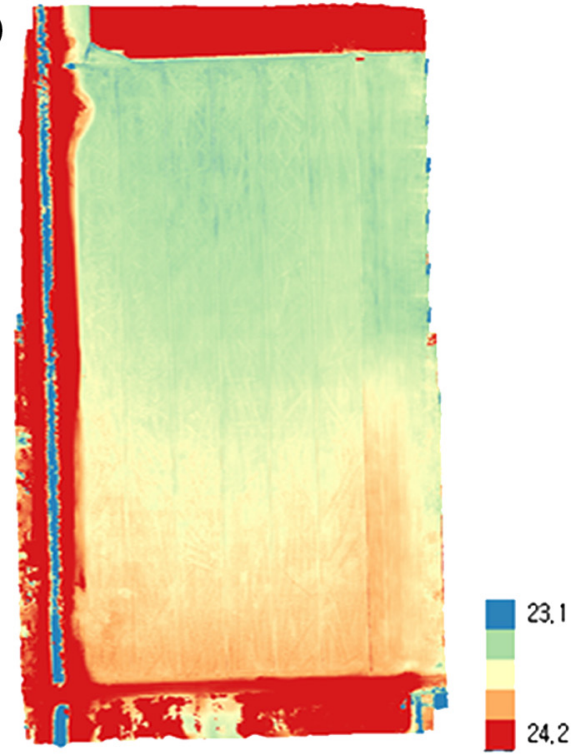

After

Fig. 2 DTM of the leveled field generated from UAS data acquired on (a) July 18, 2016 and (b) September 19, 2016.

located on each corner, and an additional two GCPs were installed between the corner targets. Considering that the total area is $\sim 7$ ha in size, the six numbers and location of GCP were reasonable and enough to remove bowling effects from UAS data. ${ }^{10}$ The coordinates of all GCP were surveyed using an APS-3 RTK GPS, manufactured by Altus Positioning Systems Incorporated (California). The horizontal and vertical accuracy of the GCP coordinates were 0.3 and $0.7 \mathrm{~cm}$, respectively. 


\section{Data Analysis}

The proposed method is composed of two major steps: (1) DTM generation using SfM and (2) evaluation of ground height model performance.

In the first step, raw data were processed using the SfM algorithm, and orthomosaic images and digital surface model (DSM) were generated. Since the data were collected without any crops in the field, the DSM can also be considered the DTM. The DTM data from each flight was used in the further analysis. UAS data sets acquired before and after land leveling were processed using the Pix4D (Pix4D, Lausanne, Switzerland) and Photoscan Pro software (AgiSoft LLC, St. Petersburg, Russia), respectively. GCPs were used to ensure precise alignment between flights. ${ }^{11}$ All GCPs were manually identified in raw images, and their coordinates were input into the Pix4D and Photoscan software for accurate georeferencing. Different SfM software was used to process UAS data due to availability of the software license at the time of data acquisition. However, previous study ${ }^{12}$ showed that both SfM software resulted in DSM layer with insignificant difference.

UAS-derived DTM were validated with the measured ground reference checkpoints to assess the performance of the UAS terrain elevation measurement capability. Those reference checkpoints were identified on the DTM images using ArcGIS 10.4 software (ESRI, Redlands, California). At each reference checkpoint, its $X$ and $Y$ coordinates were used to extract the corresponding point on the image as well as its corresponding $Z$ elevation. This procedure was carried out using the ArcToolbox Clip Function.

The discrepancy between the measured data and the data obtained with the UAS was estimated with the percent error equation

$$
\% \text { Error }=\frac{\left|Z_{\text {checkpoint }}-Z_{\mathrm{UAS}}\right|}{Z_{\text {checkpoint }}} \times 100 .
$$

The percent error is an estimator of how inaccurate a measurement is. The widely used average-error statistic mean square error (MSE) was selected for measuring the DTM accuracy. It is important to know the minimum number of checkpoints needed to guarantee a reliable assessment of DTM accuracy due to the high variability that can be found in the data. Ley ${ }^{13}$ suggested using a high number of checkpoints (around 150) to guarantee an error assessment lower than $10 \%$.

The paired $t$-test using PROC TTEST (SAS version 9.4) was used to compare ground surveyed terrain elevation measurements and UAS derived terrain elevation measurements. The $p$-value from the $t$-test and coefficient of determination $\left(R^{2}\right)$ were used as goodness of fit estimators. $R^{2}$ describes the degree of collinearity between estimated and measured data. ${ }^{14} R^{2}$ ranges from 0 to 1, with higher values indicating less error variance. Other statistics used in this study to assess the model performance were the root mean square error (RMSE)

$$
\text { RMSE }=\sqrt{\frac{1}{N} \sum_{i=1}^{n}\left(S_{i}-M_{i}\right)^{2}},
$$

where $S_{i}$ is the $i^{\prime}$ th terrain elevation value from UAS measurement, $M_{i}$ is the $i^{\prime}$ th terrain elevation value from the ground survey, and $n$ is the number of data pairs. RMSE represents the discrepancy between observations and predictions. The value of 0 indicates a perfect fit. The Nash and Sutcliffe model efficiency (NSE) was also used to quantify the model performance. It was used to see how well the measured versus estimated data fits. The NSE was calculated as

$$
\mathrm{NSE}=1-\frac{\sum_{i=1}^{n}\left(S_{i}-M_{i}\right)^{2}}{\sum_{i=1}^{n}\left(M_{i}-M_{a}\right)^{2}},
$$

where $M_{a}$ is the average of the measured values. The NSE ranges from $-\infty$ (poor model) to 1 (perfect model). A value from 0 to 1 for the NSE means that the simulated value is good as the measured mean, while values less than zero indicate an unacceptable performance. The model 
performance was evaluated using these statistical measures as well as the means and standard deviations of measured and predicted values. Percent bias (PBIAS) was also used. PBIAS measures the average tendency of the simulated data to be greater or lower than observed data. The optimal value of PBIAS is zero. Low magnitude indicates accurate model simulation. Positive values indicate model underestimation bias, and negative values indicate model overestimation bias.

$$
\text { PBIAS }=\left[\frac{\sum_{i=1}^{n}\left(M_{i}-S_{i}\right)}{\sum_{i=1}^{n} M_{i}}\right] \times 100
$$

\section{Results and Discussion}

The DTM generated from the UAS data collection before and after the leveling is shown in Fig. 2. To level the land, excavating a volume of $2691 \mathrm{~m}^{3}$ and filling and compacting a soil volume of $1794 \mathrm{~m}^{3}$ were required (Table 1). In land shaping, it is essential that the volume of material excavated be adequate to make the fills. If the cuts equal the fills without borrowing or wasting material, the earthwork is in balance. Experience has shown that the cuts-fills ratio for this location is 1.5 . The design slope in the north-south direction was $-0.15 \%$ and $0 \%$ in the west-east direction. The 7 ha of land before leveling [Figs. 1 and 2(a)] were under citrus production and divided into two pans using the natural slope. The citrus orchard was taken out of production and converted into row crop production, and the soil got introduced to the plow and off-set disk. Figure 2(a) shows where the two pans used to meet and how the land would curve downward from the south top pan into the bottom north pan. The plowing and disking were crucial for the row crop farmer to make it into one field again so that the planters/harvesters could work straight through both pans and not have to stop in the middle to move and continue planting/harvesting. However, water moved too fast at the center of the field and slower at the edges producing low irrigation uniformity and some furrows completing irrigation in a shorter time than others. Several studies have demonstrated the influence of land leveling on irrigation efficiency and uniformity. ${ }^{15,16}$

The land laser leveled is shown in Fig. 2(b). These figures showed the strategy to cut/fill the slope in the middle of the field where the two pans meet and slow down the water when irrigating crops. These figures also showed that the grade was flat from west to east and it was also more uniform from south to north with a grade of 0.15 to $100 \mathrm{~m}$ length.

A high correlation was observed between measured and estimated data (Fig. 3). A percent error of $0.3 \%$ was found between estimated and measured data. The UAS was able to estimate the ground heights with an acceptable accuracy. The slope component of the linear regression was not significantly different from one. Regression statistics showed that the slope was close to the 1:1 line $(p<0.05)$. The paired $t$-test was conducted to demonstrate that estimated data was not significantly different from measured data $(p=0.65)$ with $761 \mathrm{deg}$ of freedom. Both

Table 1 Characteristics of the land improvement analysis.

\begin{tabular}{lc}
\hline \hline Characteristics & Units \\
\hline Total field area (ha) & 7 \\
Cut area (ha) & 3.9 \\
Fill area (ha) & 3.1 \\
Cut/fill ration & 1.5 \\
Maximum slope (\%) & 0.15 \\
Percent slope in $Y$ direction & $-0.15-$ \\
Percent slope in $X$ direction & 0.00 \\
\hline \hline
\end{tabular}






Fig. 3 Field measured versus UAS estimated ground elevation.

graphical and statistical methods for the ground height models showed that measured and estimated heights matched satisfactorily with an $R^{2}=0.93$, NSE $=0.90$, PBIAS $=-0.001 \%$, and RMSE $=0.11 \mathrm{~m}$. Histogram (Fig. 4 ) of the ground elevation difference between field measurements and UAS estimates also showed reasonable agreement between measured and estimated heights.

The knowledge of the DTM of the leveled field has the potential to be used for irrigation efficiency and uniformity studies. The most important aspects of water advance and distribution over the surface are its topography and how it is managed. The DTM can be used as a survey tool to determine the grade of the soil considering the high $R^{2}$ of 0.93 observed in this study, and it

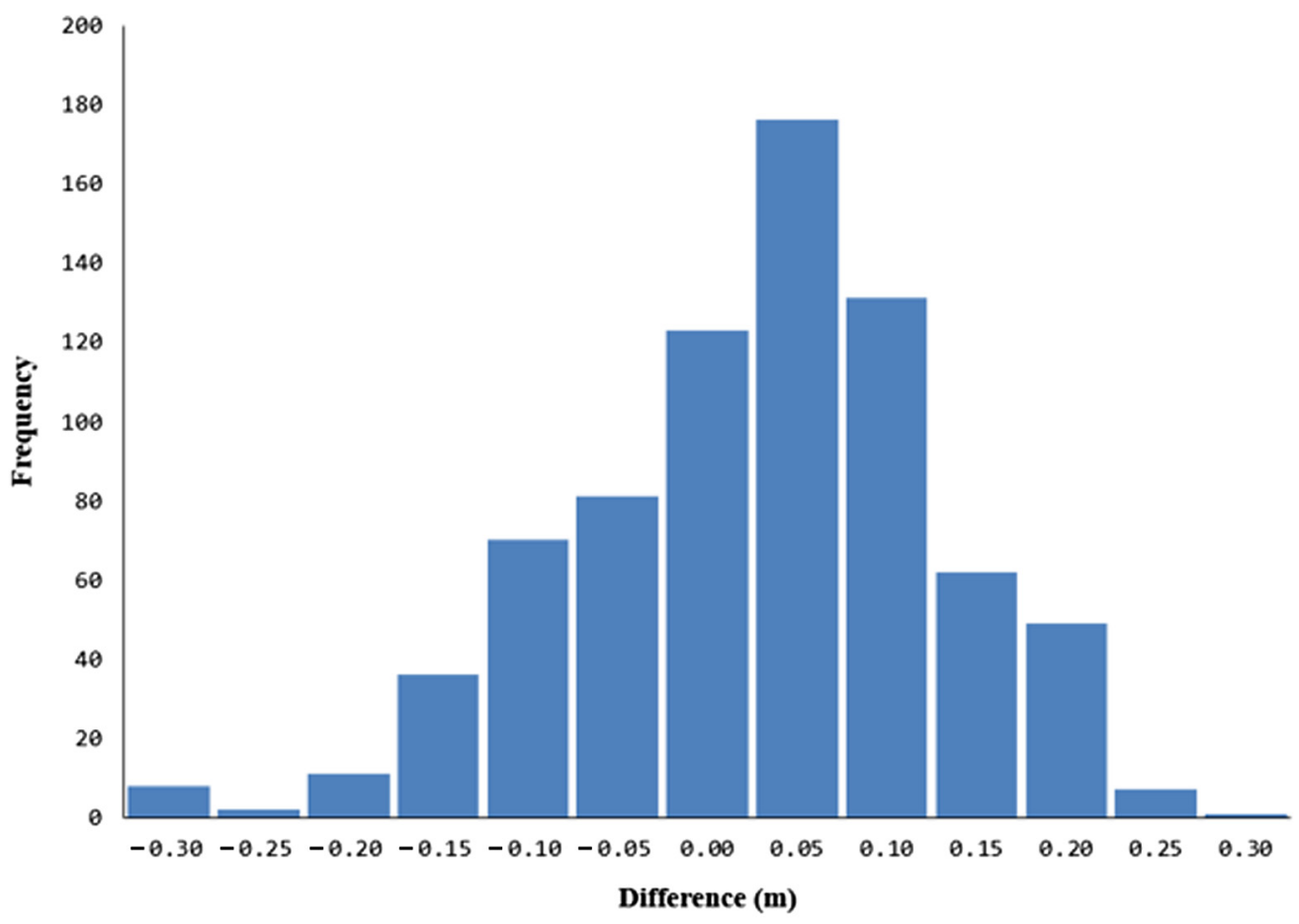

Fig. 4 Histogram of the elevation difference between field measurements and UAS derived ground elevation. 
could be utilized as an option for surveying the field previous to conducting an evaluation of the performance of the irrigation system.

\section{Conclusions}

The UAS was used to determine the topography before and after leveling the land. The ground elevation derived from UAS was compared with measured soil heights obtained with land surveying equipment. The $0.3 \%$ error and an observed value of $R^{2}=0.93$ between estimated and measured data indicate that UAS will be an efficient method to estimate ground heights with an acceptable accuracy and it can be used to assess the performance of a land leveling project or the need for a leveling retouch.

\section{Acknowledgments}

The authors would like to gratefully acknowledge the financial support from USDA NRCS Conservation Innovation Grants and USDA NIFA "Diversifying the Water Portfolio for Agriculture in the Rio Grande Basin." Technical support from Rolando Miranda, Fidi Mesa, and Ronnie Ramirez from the USDA-NRCS is also appreciated.

\section{References}

1. J. Torres-Sánchez et al., "High-throughput 3-D monitoring of agricultural-tree plantations with unmanned aerial vehicle (UAV) technology," PLOS ONE 10(6), e0130479 (2015).

2. K. M. Fornace et al., "Mapping infectious disease landscapes: unmanned aerial vehicles and epidemiology," Trends Parasitol. 30(11), 514-519 (2014).

3. J. Polo et al., "Design of a low-cost wireless sensor network with UAV mobile node for agricultural applications," Comput. Electron. Agric. 119, 19-32 (2015).

4. S. O. Ihuoma and C. A. Madramootoo, "Recent advances in crop water stress detection," Comput. Electron. Agric. 141, 267-275 (2017).

5. D. C. Paul et al., "Estimating soil moisture under low frequency surface irrigation using crop water stress index," J. Irrig. Drain. Eng. 129(1), 27-35 (2003).

6. D. C. Paul et al., "Water stress detection under high frequency sprinkler irrigation with water deficit index," J. Irrig. Drain. Eng. 129(1), 36-43 (2003).

7. D. F. Wanjura, J. L. Hatfield, and D. R. Upchurch, "Crop water stress index relationships with crop productivity," Irrig. Sci. 12, 93-99 (1990).

8. W. R. Walker, "Guidelines for designing and evaluating surface irrigation systems," FAO Irrigation and Drainage Paper 45, Rome (1998).

9. USDA-NRCS, "Natural resource conservation practice standard," Irrigation Land Levelling, Code 464 (2016), https://efotg.sc.egov.usda.gov/references/public/NM/464-STD.pdf

10. F. Mesas-Carrascosa et al., "Assessing optimal flight parameters for generating accurate multispectral orthomosaicks by UAV to support site-specific crop management," Remote Sens. 7, 12793-12814 (2015).

11. S. Harwin, A. Lucieer, and J. Osborn, "The impact of the calibration method on the accuracy of point clouds derived using unmanned aerial vehicle multi-view stereopsis," Remote Sens. 7(9), 11933-11953 (2015).

12. R. Niederheiser et al., "Deriving 3-D point clouds from terrestrial photographs-comparison of different sensors and software," in Int. Archives of the Photogrammetry, Remote Sensing and Spatial Information Sciences, 41(B45), pp. 685-692 (2016).

13. R. G. Ley, "Accuracy assessment of digital terrain models," in Proc. Auto-Carto London, Vol. 1, pp. 455-464 (1986).

14. D. N. Moriasi et al., "Model evaluation guidelines for systematic quantification of accuracy in watershed simulations," Trans. ASABE 50(3), 885-900 (2007).

15. D. D. Fangmeier et al., "Influence of land leveling precision on level-basin advance and performance," Trans. ASABE 42(4), 1019-1026 (1999). 
16. E. Playan, J. M. Faci, and A. Serreta, "Modeling microtopography in basin irrigation," J. Irrig. Drain. Eng. 122(6), 339-347 (1996).

Juan Enciso is a biological and agricultural engineer and associate professor of Texas A\&M AgriLife Research. He is interested in applying physical and mathematical principles and technologies to solving problems related to irrigated agriculture and management of soil and water resources. Some of the technologies involve using computational tools, remote sensing, and statistics to optimize the quality and quantity of water resources.

Biographies for the other authors are not available. 